\title{
Study on FuzzPID control of Shared Chamber Air Suspension for ride comfort
}

\author{
Mei Li ${ }^{1, a}$, Dezhi Wang ${ }^{1, b}$,Shaobo Zhang ${ }^{1}$,Silong $\operatorname{Tan}^{1}$ and Yingcong $\mathrm{Ji}^{1}$ \\ ${ }^{1}$ College of Mechanical and Electrical Engineering , Hainan University, Haikou 570228, China
}

\begin{abstract}
In order to study a new type of air suspension system, the quarter dynamic model of semi-active suspension system is established based on FuzzPID control theory; At the same time, a test bench is established. Through analyzing the data which got in simulation and test, the result show that the performance of air spring parameters has obvious improvement on the acceleration of the vehicle body. Butthe performance on the deflection of the suspension and the dynamic tire load is not the same. By changing the frequency of sinusoidal excitation, the specific performance of ride comfort parameters in different sinusoidal excitation has been studied.
\end{abstract}

\section{Introduction}

Air suspension can provide variable stiffness according to different sprung masses and road disturbances. Therefore, the equipment rate has increased a lot recently and many novel air suspensions have been proposed, such as interconnected type, additional air chamber type and double air chamber type. L. Zhongxing proposed a horizontally interconnected air suspension structure and analysed the influence of different parameters on vehicle ride comfort. He indicated that this type of suspension can reduce body damage and increase vehicle usage time[1]; Z. Zehua established a dual chamber air suspension model,which has provided a theoretical basis for the forward design of this suspension type[2];M.M. Moheyelde in combined dual air chamber air springs with active and passive suspensions separately. He analyzed the influence of parameters such as chamber pressure and connecting pipe inner diameter on the suspension[3].However, there is no related research on Shared Chamber Air Suspension(SCAS).SCAS consists of one shared air chamber, connecting pipes and air springs, which was original developed by authors of this paper. Each spring in SCAScan be connected by connecting pipes. The connected state of the spring and the air chamberis controlled by the solenoid valve.

Theapplication of modern intelligent control technology in air suspension has become the hot research topiccurrently.H.D Choi proposed a new fuzzy preview control method for an electro-hydraulic suspension system to further improve the suspension performance and extend the results to practical situations [4].A. Shehata demonstrated the application of fuzzy logic technique to design a controller for the traditional active vehicle suspension system. He improved the suspension system performance by altering the number and arrangement of the
rules[5].In this study, considering the superior performance in nonlinear time-varying system, Researchers found FuzzPID controller was a good choice to combine with this new type air suspension.

\section{The establishment of dynamic models}

$1 / 4$ vehicle 2 DOF dynamics model involves the least design parameters and can fully reflect the performance indexes of air suspension[6]. Based on Newton mechanics laws and shared chamber air spring model, 1/4 vehicle dynamics model is established which shown as equation 1 and Fig. 1.

$$
\left\{\begin{array}{l}
M Z_{2}=C\left(\dot{Z}_{1}-\dot{Z}_{2}\right)+K_{2}\left(Z_{1}-Z_{2}\right)-F_{s} \\
m Z_{1}=C\left(\dot{Z}_{2}-\dot{Z}_{1}\right)+K_{2}\left(Z_{2}-Z_{1}\right)+K_{1}\left(q-Z_{1}\right)+F_{s}
\end{array}\right.
$$

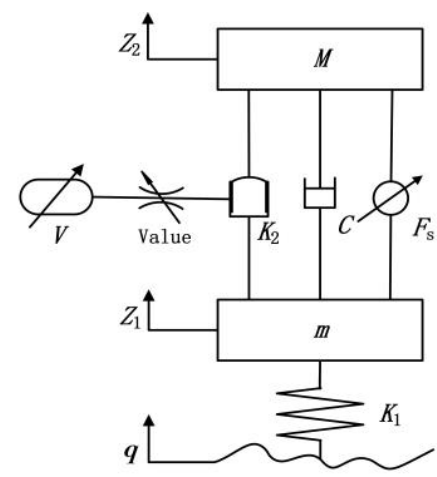

Figure 1. The quarter SCAS dynamic model.

Where $\boldsymbol{M}$ is sprung mass and $\boldsymbol{m}$ is unsprung mass. $\boldsymbol{Z}_{\mathbf{1}}$ and $\boldsymbol{Z}_{\mathbf{2}}$ are unsprung and sprung mass displacements respectively. $\boldsymbol{C}$ is suspension damping. $\boldsymbol{K}_{\mathbf{1}}, \boldsymbol{K}_{\mathbf{2}}$ are tire and 
suspension stiffness respectively. $\boldsymbol{F}_{\boldsymbol{s}}$ is the adjustable force. $\left(Z_{2}-Z_{1}\right)$ is the deflection of the suspension(Def). $\boldsymbol{q}$ is the sinusoidal input. the frequency of which is as the same as spring system. $\boldsymbol{K}_{\mathbf{1}}\left(\boldsymbol{Z}_{\mathbf{1}}-\boldsymbol{q}\right)$ is the dynamic tire load(DTL).

\subsection{The shared chamber air spring dynamic stiffness model}

According to the shared chamber air spring dynamic stiffness solution process, this study just need to solve the equivalent maximum pressure and equivalent minimum pressure at the height.At the working height of the air spring, the product of the equivalent pressure difference and the effective area are taken as the equivalent load difference, then the dynamic stiffness can be got[7].

When the initial pressure of the shared chamber is 0.15 $\mathrm{MPa}$ and the diameter of connecting pipe is $16 \mathrm{~mm}$, the equivalent pressure difference of the air spring working height can be got at different volume ratios and different excitation frequencies. These data will be fit in Surface Fitting Tool (sftool) and equivalent pressure difference $p(x, y)=\Delta p_{e q}\left(p_{0}=0.15 \mathrm{Mpa}\right)$ will be obtained

When the diameter of connecting pipe is constant, in addition to the influence of the initial pressure, the equivalent pressure difference can also be affected by the volume ratio $\left(V_{\mathrm{f}} / V_{\mathrm{m}}\right)$ and the excitation frequency. By fitting the difference between the equivalent pressure of other initial pressure and the equivalent pressure of $0.15 \mathrm{MPa}$, the difference between the $\Delta p_{e q}$ and the other initial pressure can be obtained. The fitting surface is shown in Fig. 2, which marked as $p p(\mathrm{x}, \mathrm{y})=\Delta\left(\Delta p_{\text {eq }}\right)$.

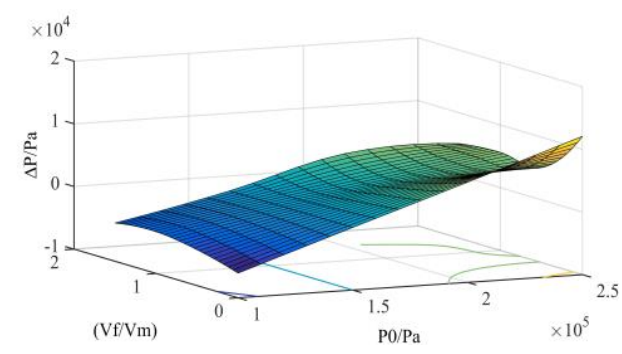

Figure 2.Fitting surface.

The fitting function of each initial pressure can be obtained by add $p(x, y)$ and $p p(\mathrm{x}, \mathrm{y})$, which can be described as equation 2 .

$$
\Delta p_{\mathrm{eq}}=P(x, y)+P P(x, y)
$$

When the air spring working height is set at h0 and sinusoidal excitation amplitude is $\mathrm{A} 0$, the load(F) on the air chamber under the equivalent air pressure can be expressed as equation 3 :

$$
F=p_{\text {eq }}\left(h=h_{0}\right) \cdot A_{e}\left(h=h_{0}\right)
$$

The definition of dynamic stiffness $\mathrm{k}$ is expressed as equation 4:

$$
K_{d}=F / 2 A_{0}
$$

After error analysis and experimental data comparison, the dynamic stiffness model of the spring system is obtained as equation 5 :

$$
\begin{gathered}
K_{2}(x, y, z)=\left(13720-10370 x+2337 y+7951 x^{2}+484.8 x y-939.8 y^{2}-3790 x^{3}-\right. \\
2690 x^{2} y-229.1 x y^{2}+148.3 y^{3}+923 x^{3} y+592.3 x^{2} y^{2}+9.398 x y^{3}-10.08 y^{4}- \\
162.5 x^{3} y^{2}-12.34 x^{2} y^{3}-0.08918 x y^{4}+0.2484 y^{5}+0.04189 z+6.246 \times 10^{-7} z^{2}- \\
\left.0.1206 x z-1.5 \times 10^{-12} z^{3}-1.304 \times 10^{-8} x z^{2}-0.064 x^{2} z\right) \cdot A_{e}\left(h=h_{0}\right) / 2 A_{o}
\end{gathered}
$$

where $x=V_{\mathrm{f}} / V_{\mathrm{m}}$, Excitation frequency $y=f, z=p_{0}$.

\subsection{Design of FuzzPID controller}

The FuzzPID controller can be mainly divided into PID and Fuzzy controller, shown as Fig.3

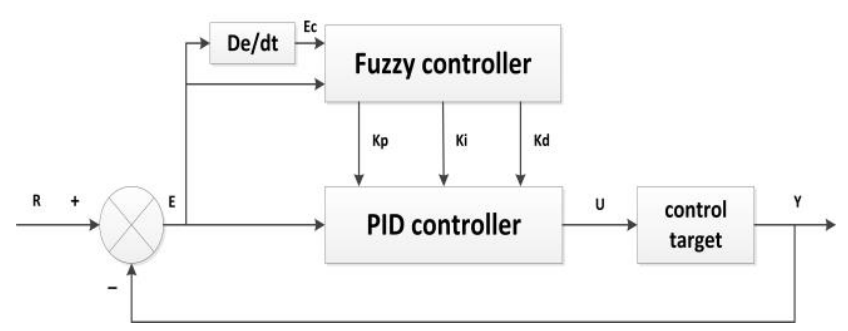

Figure 3. The Fuzzy-PID controller schematic.

\subsection{PID controller}

The PID controller consists of proportional(P), integral(I) and derivative(D), which takes the difference of control amount from default value as input[8].Parameter is tuned by gains $\left(\mathrm{K}_{\mathrm{p}}, \mathrm{K}_{\mathrm{i}}, \mathrm{K}_{\mathrm{d}}\right)$ of Proportional, Integral and Derivative modules. The PID control algorithm is given by equation 6 .

$u(t)=K_{p} e(t)+K_{i} \int e(t) d t+K_{d} \frac{d e(t)}{d t}$

where $u(t)$ is the output of control signal. $e(t)$ is the difference between control amount and the default value.

In this study $e(t)$ is the difference of vehicle body acceleration(ACC)from its default value(zero). As normal circumstances, the lower the ACC is the better theride comfort is. Simultaneously, adjustable force $\mathrm{F}_{\mathrm{s}}$ is output. In PID controller, the optimal performance is got by tuning the effects of each units. through trial and error method. It is found that $\mathrm{K}_{\mathrm{p}}=2400, \mathrm{~K}_{\mathrm{i}}=8, \mathrm{~K}_{\mathrm{d}}=1.5$.

\subsection{Fuzzy controller}

As a nonlinear time-varying system, semi-active suspension system cannot be adjusted dynamically by conventional PID controller. While fuzzy logic has the capability of understanding the imprecision and uncertainty of the real world .So it can provide a right balance between significance and precision[9]. This cap ability makes it capable to cover many complex systems which classical controllers cannot. Therefore, there is a composite control method combining PID controller with Fuzzy controller. 
The fuzzy controller is a Mamdani type with two inputs and three outputs system. Both input and output consist of seven member ship functions each and these functions form $3 * 49$ rules. The surfaces are shown as Fig. 4 and from the surfaces the ranges of input and output can be found.
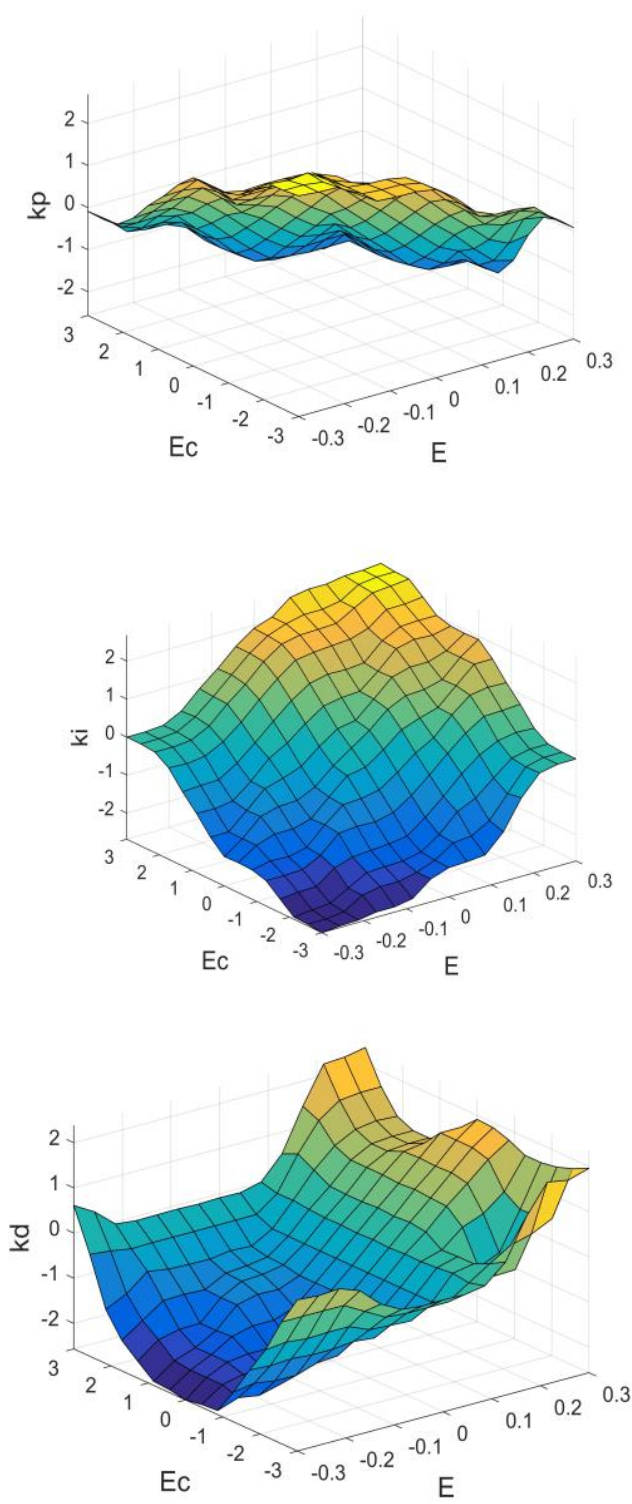

Figure 4. Surfaces of rules.

These three PID controller parameters $\Delta k_{p}, \Delta k_{i}, \Delta k_{d}$ are the outputs of the fuzzy controller adjustment amounts. Though the adjust ment of PID controller, the final $k_{p}, k_{i}, k_{d}$ have been got.The relationship between $k_{p}, k_{i}, k_{d}$ and $\Delta k_{p}, \Delta k_{i}, \Delta k_{d}$ are shown as equation 7 .

$$
\left\{\begin{array}{l}
k_{p}=k_{p 0}+\Delta k_{p} \\
k_{i}=k_{i 0}+\Delta k_{i} \\
k_{d}=k_{d 0}+\Delta k_{d}
\end{array}\right.
$$

Where $\mathrm{k}_{\mathrm{p} 0}, \mathrm{k}_{\mathrm{i} 0}, \mathrm{k}_{\mathrm{d} 0}$ are the optimal control parameters obtained by conventional PID control.

\section{Establishment of test bench}

The test bench is mainly assembled by INSTRON 8800 CNC hydraulic servo excitation system, pressure sensor, data acquisition system, computer and LabView-based test software, which is shown as Fig.5.

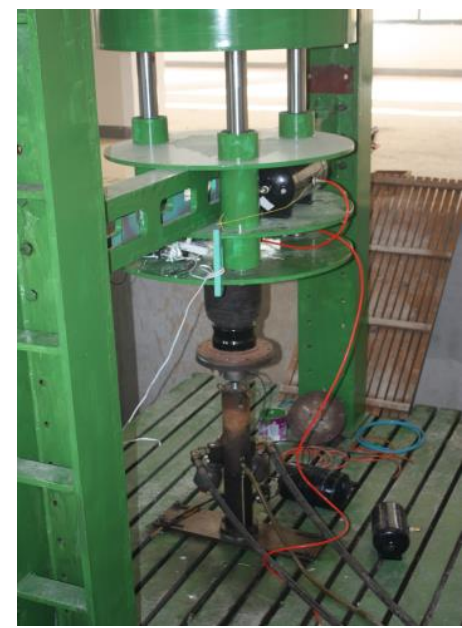

Figure 5. experimental device.

The upper part of the suspension is fixed, and the lower part is excited by the excitation system. Air pressure at both ends of the connecting line can be collected with baroceptor [7].INSTRON $8800 \mathrm{CNC}$ hydraulic servo excitation system can collect air suspension load and displacement as well as acceleration data. Controlling variable method was adopted to study variable parameter separately and these parameters are given by Table 1 .

Table 1. Variable parameters of air spring.

\begin{tabular}{ll}
\hline \multicolumn{1}{c}{ Parameters } & Values \\
\hline Connecting pipe inner diameter $/ \mathrm{mm}$ & $8,12,16,20$ \\
Shared chamber volume $/ \mathrm{L}$ & $0,5,10,15$ \\
Shared chamber pressure $/ \mathrm{MPa}$ & $0.1,0.15,0.2,0.25$ \\
Excitation frequency $/ \mathrm{Hz}$ & $0.5 \sim 10$ \\
\hline
\end{tabular}

\section{Analysis of simulation and test results}

The ride comfort performance of SCAS system is affected by connecting pipe diameter, shared chamber volume and shared chamber pressure. These three factors will be analysed separately. A passenger vehicle was taken as the research object and the parameter is given inTable. 2 .

Table 2. Parameters of vehicle.

\begin{tabular}{lcc}
\hline \multicolumn{1}{c}{ Parameters } & & Values \\
\hline Sprung mass & $\mathrm{M} / \mathrm{kg}$ & 412 \\
Unsprung mass & $\mathrm{m} / \mathrm{kg}$ & 43 \\
Tires tiffness & $\mathrm{K}_{1} /(\mathrm{N} / \mathrm{m})$ & 197000 \\
Suspension stiffness & $\mathrm{K}_{2} /(\mathrm{N} / \mathrm{m})$ & $\begin{array}{c}\text { changing with spring } \\
\text { parameters } \\
\text { suspension damping }\end{array}$ \\
\hline
\end{tabular}




\subsection{Influence of connecting pipe diameter.}

$0.15 \mathrm{MPa}$ is set to be the shared chamber pressure and the shared chamber volume is set to $10 \mathrm{~L}$. Stimulate the damping effect with different diameters, the results are shown in Fig.6.

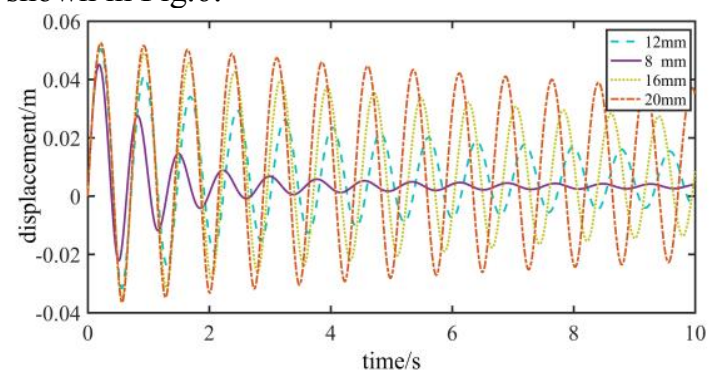

Figure 6. Damping effect with difference diameters.

It can be observed inFig. 6 that with the increases of diameters, the damping effect of spring getting lower. When diameter increased to $16 \mathrm{~mm}$, the damping effect has become very little. As shown in Fig.7, when diameter comes to $12 \mathrm{~mm}$, the influence of diameter on suspension system has become indistinguishable. Because the damping effect of the air spring is not in the scope of this study, $16 \mathrm{~mm}$ is used as the connecting pipe diameters in the subsequent research.

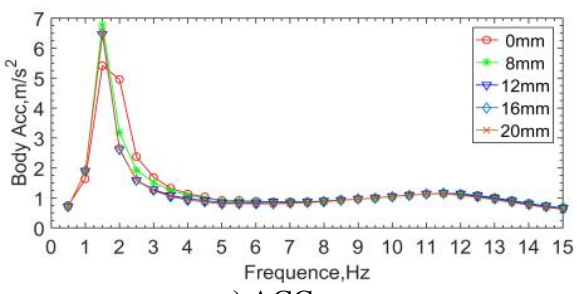

a ) ACC

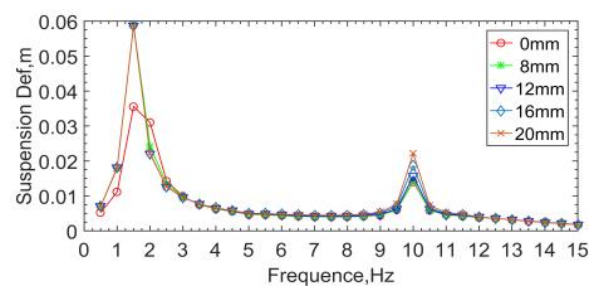

b) Def

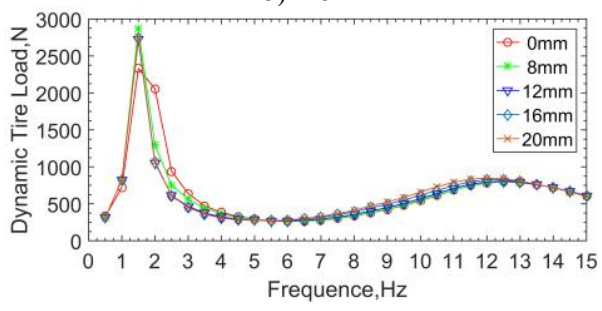

c) DTL

Figure 7. Influence of connecting pipe inner diameter on body parameters.

\section{Influence of shared chamber volume}

When shared chamber pressure is $0.15 \mathrm{MPa}$ and diameteris $16 \mathrm{~mm}$, the simulation and test results on vehicle ride comfort with different shared chamber volume are shown as Fig. 8 and Table. 3 .

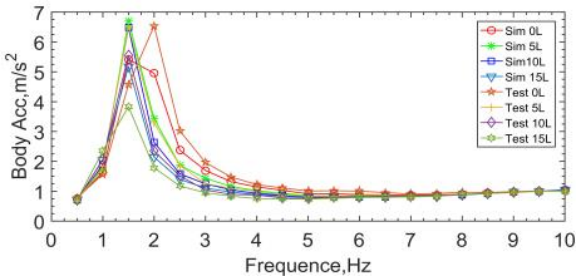

a) $\mathrm{ACC}$



b) Def

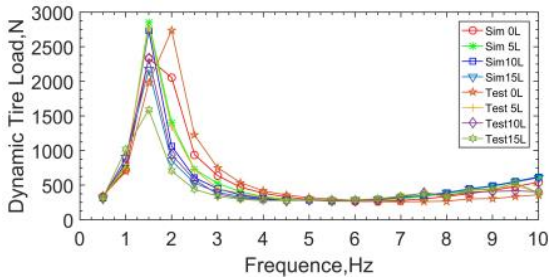

c) DTL

Figure 8. Influences of shared chamber volume on suspension parameters.

Table 3. Performance of vehicle ride comfort at 4 to $8 \mathrm{~Hz}$.

\begin{tabular}{|c|c|c|c|c|c|c|}
\hline \multirow{2}{*}{\multicolumn{3}{|c|}{ Parameter index }} & \multicolumn{4}{|c|}{ shared chamber volume } \\
\hline & & & $0 \mathrm{~L}$ & $5 \mathrm{~L}$ & $10 \mathrm{~L}$ & $15 \mathrm{~L}$ \\
\hline \multirow{4}{*}{$\begin{array}{l}\text { RMS } \\
\text { of } \\
\text { ACC }\end{array}$} & \multirow{2}{*}{\multicolumn{2}{|c|}{$\begin{array}{l}\mathrm{Sim} / \mathrm{m} \mathrm{s}^{-2} \\
\text { Increase } / \%\end{array}$}} & 0.9336 & 0.8480 & 0.8306 & 0.8164 \\
\hline & & & & $9.167 \%$ & $11.030 \%$ & $12.547 \%$ \\
\hline & \multicolumn{2}{|c|}{ Test $/ \mathrm{m} \mathrm{s}^{-2}$} & 1.0124 & 0.8673 & 0.8211 & 0.7925 \\
\hline & \multicolumn{2}{|c|}{ Increase $/ \%$} & & $14.332 \%$ & $18.896 \%$ & $21.721 \%$ \\
\hline \multirow{4}{*}{$\begin{array}{l}\text { RMS } \\
\text { of } \\
\text { Def }\end{array}$} & \multicolumn{2}{|c|}{$\operatorname{Sim} / \mathrm{m} \mathrm{s}^{-2}$} & 0.004641 & 0.004859 & 0.004986 & 0.005008 \\
\hline & \multicolumn{2}{|c|}{ Increase $/ \%$} & & $-4.697 \%$ & $-7.434 \%$ & $-7.991 \%$ \\
\hline & \multicolumn{2}{|c|}{ Test $/ \mathrm{m} \mathrm{s}^{-2}$} & 0.004342 & 0.004906 & 0.005048 & 0.005146 \\
\hline & \multicolumn{2}{|c|}{ Increase $/ \%$} & & $-12.98 \%$ & $-16.26 \%$ & $-18.51 \%$ \\
\hline \multirow{4}{*}{$\begin{array}{l}\text { RMS } \\
\text { of } \\
\text { DTL }\end{array}$} & \multicolumn{2}{|c|}{$\mathrm{Sim} / \mathrm{m} \mathrm{s}^{-2}$} & 302.1447 & 306.1988 & 298.3560 & 289.2054 \\
\hline & \multicolumn{2}{|c|}{ Increase $/ \%$} & & $-1.342 \%$ & $1.254 \%$ & $4.282 \%$ \\
\hline & \multicolumn{2}{|c|}{ Test $/ \mathrm{m} \mathrm{s}^{-2}$} & 302.7409 & 308.9357 & 307.0314 & 309.3786 \\
\hline & \multicolumn{2}{|c|}{ Increase $/ \%$} & & $-2.046 \%$ & $-1.417 \%$ & $-2.193 \%$ \\
\hline \multirow{2}{*}{\multicolumn{2}{|c|}{$\begin{array}{l}\text { Comprehensive } \\
\text { Improvement }\end{array}$}} & \multicolumn{2}{|c|}{ Simulation } & $4.124 \%$ & $4.948 \%$ & $6.173 \%$ \\
\hline & & \multicolumn{2}{|l|}{ Test } & $5.045 \%$ & $7.060 \%$ & $8.074 \%$ \\
\hline
\end{tabular}

As shown in Fig. 8 and Table.3, the simulation and test results indicate a good consistency, this will be elaborate in the next paragraphs. The little deviation between test and simulation data was mainly caused by two factors, the additional friction and torque in test bench and the ignored effect caused by the self-damping of spring in simulation.

Fig. 8 shows that in the resonance frequency range of 1 $\mathrm{Hz}$ to $2 \mathrm{~Hz}$, both test and simulation reach their maximum values at each working condition. When it comes to the range of $4 \mathrm{~Hz}$ to $8 \mathrm{~Hz}$, the most sensitive frequency range of human internal organs, all of the values have an obvious decline.

Table. 3 lists the average RMS values of vehicle ride comfort at 4 to $8 \mathrm{~Hz}$. Compared with zero volume, the 
average RMS values of ACC has a significant decrease with the increases of volume. Through the calculation of the simulation and test results, it is found in simulation that $5 \mathrm{~L}$ decreased by $6.170 \%, 10 \mathrm{~L}$ decreased by $9.876 \%, 15 \mathrm{~L}$ decreased by $11.054 \%$. The improvement of theseparameters become more obvious when it comes to test results, $14.332 \%, 18.896 \%$ and $21.721 \%$ decrease was got separately with $5 \mathrm{~L}, 10 \mathrm{~L}$ and $15 \mathrm{~L}$.

The performance of suspension is mutually restricted to some extent. Usually, each sub-object function cannot get the optimal value at the same time. Therefore, the weighting method is often used to give weight to each subobject. Refer to QC/T474-2011bus ride comfort evaluation indicators and limits, the weighting factors of ACC, Def and DTL were determined to be $0.65,0.25$ and 0.15 separately. As listed in Table.3, although decreased with the increase of shared chamber volume, the performances of Def and DTL still have varying degrees of improvement with comprehensive performance for every volume.

\section{Influence of shared chamber pressure}

In this part, the diameter is $16 \mathrm{~mm}$ and shared chamber volume is $10 \mathrm{~L}$, the simulation and test results on vehicle ride comfort are with different shared chamber pressure shown as Fig.9 and Table.3.
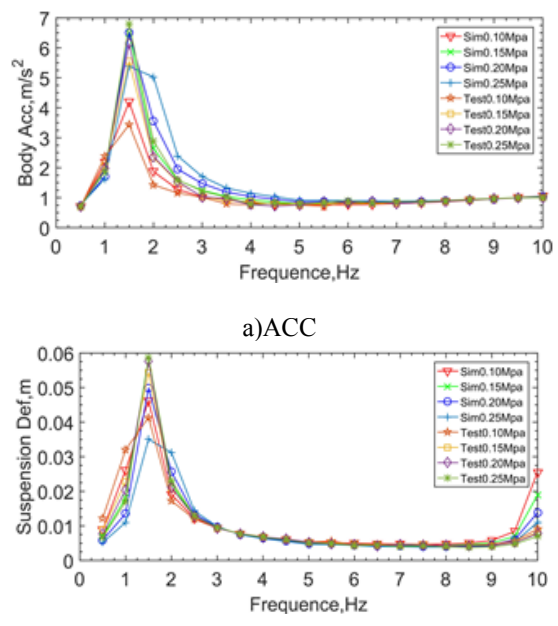

b)Def



c) DTL

Figure 9. Influences of shared chamber pressure on suspension parameters.

As shown in Fig.9 and Table.4, different from the influence of shared chamber volume, an obvious gap was found between simulation and test results in shared chamber pressure. The reason is that except what has been analysed above, turbulence was ignored in simulation. Turbulence can be complex with different shared chamber pressure and it would not be analysed in this paper.
Fig.9 shows that with the decrease of shared chamber pressure, in the resonance frequency range of $1 \mathrm{~Hz}$ to $2 \mathrm{~Hz}$, the values of ride comfort also rapidly falls to a very low range after reaching the maximum value. This can be good for the ride comfort. As listed in Table.4, in the range of $4 \mathrm{~Hz}$ to $8 \mathrm{~Hz}$,similar to what has been analysed in the previous sections, ACC performance improved as the decrease of pressure. But when weights were added to these parameters, both simulation and test results have an obvious improvement in comprehensive performance.

Table 4. Performance of vehicle ride comfort at 4 to $8 \mathrm{~Hz}$

\begin{tabular}{|c|c|c|c|c|c|}
\hline \multirow{2}{*}{\multicolumn{2}{|c|}{ Parameter index }} & \multicolumn{4}{|c|}{ shared chamber pressure } \\
\hline & & $0.25 \mathrm{MPa}$ & $0.20 \mathrm{MPa}$ & $0.15 \mathrm{MPa}$ & $0.10 \mathrm{MPa}$ \\
\hline \multirow{4}{*}{$\begin{array}{l}\text { RMS } \\
\text { of } \\
\text { ACC }\end{array}$} & \multirow{2}{*}{$\begin{array}{l}\text { Sim } / \mathrm{m} \mathrm{s}-2 \\
\text { Increase } / \%\end{array}$} & 0.9443 & 0.8951 & 0.8414 & 0.7997 \\
\hline & & & $5.210 \%$ & $10.897 \%$ & $15.313 \%$ \\
\hline & Test $/ \mathrm{m} \mathrm{s}-2$ & 0.8477 & 0.8074 & 0.8043 & 0.7904 \\
\hline & Increase $/ \%$ & & $4.474 \%$ & $5.111 \%$ & $6.757 \%$ \\
\hline \multirow{4}{*}{$\begin{array}{l}\text { RMS } \\
\text { of } \\
\text { Def }\end{array}$} & $\mathrm{Sim} / \mathrm{m} \mathrm{s}-2$ & 0.004576 & 0.004552 & 0.004986 & 0.005107 \\
\hline & Increase $/ \%$ & & $0.519 \%$ & $-8.960 \%$ & $-11.60 \%$ \\
\hline & Test $/ \mathrm{m} \mathrm{s}-2$ & 0.004827 & 0.004830 & 0.004847 & 0.004978 \\
\hline & Increase $/ \%$ & & $-0.066 \%$ & $-0.428 \%$ & $-3.133 \%$ \\
\hline \multirow{4}{*}{$\begin{array}{l}\text { RMS } \\
\text { of } \\
\text { DTL }\end{array}$} & $\mathrm{Sim} / \mathrm{m} \mathrm{s}-2$ & 297.7414 & 299.0196 & 308.6814 & 329.5182 \\
\hline & Increase $/ \%$ & & $-0.429 \%$ & $-3.674 \%$ & $-10.67 \%$ \\
\hline & Test $/ \mathrm{m} \mathrm{s}-2$ & 286.2213 & 295.8546 & 297.3055 & 298.6093 \\
\hline & Increase $/ \%$ & & $-3.366 \%$ & $-3.873 \%$ & $-4.328 \%$ \\
\hline \multirow{2}{*}{\multicolumn{2}{|c|}{$\begin{array}{l}\text { Comprehensive } \\
\text { Improvement }\end{array}$}} & tion & $3.192 \%$ & $3.747 \%$ & $4.686 \%$ \\
\hline & & Test & $2.327 \%$ & $2.379 \%$ & $2.622 \%$ \\
\hline
\end{tabular}

\section{Conclusion}

This studyinvestigates a novel dynamic model of air suspension(SCAS).Meanwhile, FuzzPID controller was utilized with SCAS. The influence of SCAS parameters on ride comforthas been analyzed, the results indicate thathow larger shared chamber volume and lower shared chamber pressure contribute to the improvement of ACC; Although Def and DTL cannot get the optimal value at the same time, when weights are added to these parameters, the comprehensive performance still have an improvement. Furthermore, the specific performance of ride comfort parameters in different sinusoidal excitation has been studied, this can be a good reference for next study on Realtime suspension control system.

\section{Acknowledgments}

The authors wish to acknowledge the generous contributions of project team of the Electronic Controlled Air Suspension System, as well as to acknowledge the financial support from Hainan Provincial Natural Science Foundation of China (Grants NO.518QN209),University Research Project of The Education Department of Hainan Provincial (Grants NO.Hnky2019ZD-2) and National Natural Science Foundation of China(Grants NO.5157524 and NO.51305111).

\section{References}


1. L. Zhong Xin, Y. J. Hong Jiang, X. Xu, Study on Torsion-Eliminating Performance of Laterally Interconnected Air Suspension, J. Applied Mechanics and Materials.596,3335,(2014)

2. Z. Ze Hua, Y.Wen Sheng, Study on the stiffness of double chamber air spring rubber diaphragm, J.Vibration and shock.37, 204-210, (2018).

3. M.M. Moheyeldein, A M. Abd-El-Tawwab,K.A. Abd Elgwwad, M.M.M. Salem, An analytical study of the performance indices of air spring suspensions over the passive suspension, J. Beni-Suef University Journal of Basic and Applied Sciences,(2018).

4. H. D. Choi, C. Joo Lee,Fuzzy Preview Control for Half-vehicle Electro-hydraulic Suspension System, J.International Journal of Control, Automation and Systems.16,2489-2500, (2018)

5. A. Shehata, H. Metered and A.H. Oraby,Vibration Control of Active Vehicle Suspension System Using Fuzzy Logic Controller, J.Vibration Engineering and Technology of Machinery.23,389-399,(2015)

6. Y. Zhi Sheng, Automotive theory, M. China Machine Press, (2009)

7. L. Mei, Mechanism Analysis on Dynamic Characteristics of Air Spring System with Auxiliary Chamber,(phD thesis, Zhen Jiang, China, 2012)

8. H. Khodadadi, H. Ghadiri, Self-tuning PID controller design using fuzzy logic for half car active suspension system,Int. J. Dynam. Control.6,224-232,(2018)

9. O. Demir, I. Keskin, S.Cetin, Modeling and control of a nonlinear half-vehicle suspension system: a hybrid fuzzy logic approach. Nonlinear Dyn,67,2139-2151 (2012) 